\title{
Influence of Annealing Conditions on Structural Development of Cryo Rolled FeSi Steel
}

\author{
T. Kvackaj*, J. Bidulska, R. Bidulsky, A. Kovacova, R. Kocisko, P. Bella, \\ M. LUPTAK, J. BACSO \\ Faculty of Metallurgy, Technical University of Košice, Vysokoškolská 4, 04200 Košice, Slovakia \\ Non grain oriented isotropic electrical steels, commercially called NGOES, were investigated in cryogenic \\ temperature conditions. At cryogenic temperatures plastic deformations form strong structural heterogeneities \\ in the sample thickness. Samples processed by cryo rolling show a bigger storage energy. To achieve abnormal \\ grain growth through the process of static recrystallization, the annealing conditions were applied to the deformed \\ samples. Moreover, minimal magnetic losses were reached when mean grain size diameter was approximately \\ $150 \mu \mathrm{m}$.
}

DOI: 10.12693 /APhysPolA.126.184

PACS: 75.50.Bb, 81.05.Bx, 81.40.Rs, 81.40.Ef

\section{Introduction}

It is well know that silicon non grain oriented isotropic electrical steel (NGOES) sheets are produced with the final thickness of $0.35-0.65 \mathrm{~mm}$ and their production consists of hot rolling (approximately $1.2 \mathrm{~mm}$ thick), followed by cold rolling (up to final thickness) and annealing. Cold strip rolling produces the deformed and fine grains (FG) structure. Moreover, minimal magnetic losses are reached when a mean grain size diameter is approximately $150 \mu \mathrm{m}$ and more. Therefore cold rolling, followed by annealing process, are very important to control the static recrystallization (SR) and abnormal grain size, which allows the formation of final coarse-grained (CG) structures with positive effects on the mechanical properties, thermal conductivity, saturation polarization and magnetic permeability. The formation of CG structures is one of ways for achieving the low magnetic losses in NGOES and its higher efficiency for application in e.g. electrical automobile engines and hybrid motors. The effective structure control can be realized by modification of chemical composition, namely by particles and phase transformation controlling, mechanical processing in hot or cold conditions and softening of deformed structures $[1,2]$. Nowadays, a special method of the cold rolling process, by which structures are being formed, is the rolling at cryogenic temperatures. Since only few researchers are involved in plastic deformation of steels at cryogenic temperatures $[3,4]$, this article is focused on the structure formation of steel through mechanical processing at a cryogenic temperature, followed by annealing processes.

\section{Experimental procedures}

The experimental work was carried out on FeSi steel base with chemical composition: $\mathrm{C}-0.003 \%, \mathrm{Mn}-0.234 \%$, $\mathrm{Al}-0.41 \%$, Si-3.46 \%, P-0.009\%, S-0.001\%, Cu- $0.018 \%$, Fe-95.8\%. Sample sizes before the rolling were: $h \times b \times l=$

*corresponding author; e-mail: tibor.kvackaj@tuke.sk
$0.65 \times 30 \times 200 \mathrm{~mm}^{3}$. The samples were laboratory rolled in Duo 210 mill at cryogenic temperature. Cryogenic temperature was achieved by cooling of the samples in liquid nitrogen. The deformation of sample thickness through the cold rolling was $\varepsilon_{\text {cold }}=20 \%$ in a single pass. The samples were annealed in following conditions: $T_{\text {annealing }} \in(800,1100)^{\circ} \mathrm{C}, t_{\text {annealing }}=20 \mathrm{~min}$ with $v_{\text {ave,reheat }}=0.2^{\circ} \mathrm{C} / \mathrm{s}, v_{\text {ave }, \text { cooling }}=0.5^{\circ} \mathrm{C} / \mathrm{s}$ without special annealing atmosphere.

\section{Results and discussion}

The structure formation through rolling at cryogenic temperatures is given in Fig. 1a. The observed structure shows formation of potential sites of nuclei for SR. Nucleation sites are predominantly formed on high-angle grain boundaries (HAGBs) and consequently on the twins and deformation bands. The ability to form a larger nucleation surface through processing of samples at cryogenic temperature is given by partial suppressing of dynamic recovery in the surface layer but with strong suppressing of dynamic recovery in the central part of thickness, which create more elongated grains with deformation twining and deformation bands. It can be assumed that inhomogeneity in dynamic recovery depends on the temperature gradient in the sample thickness (surface lay-
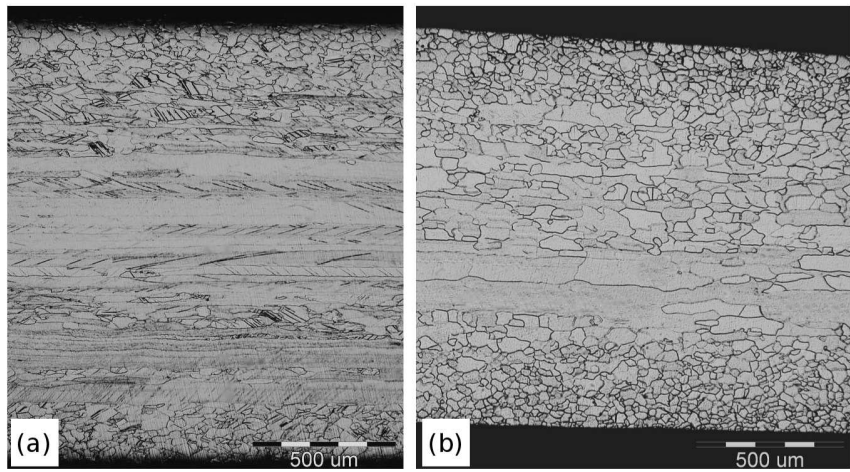

Fig. 1. (a) the structure rolled at $\mathrm{T}_{\text {cryogenic }}$, (b) the structure annealed at $800{ }^{\circ} \mathrm{C} / 20 \mathrm{~min}$. 

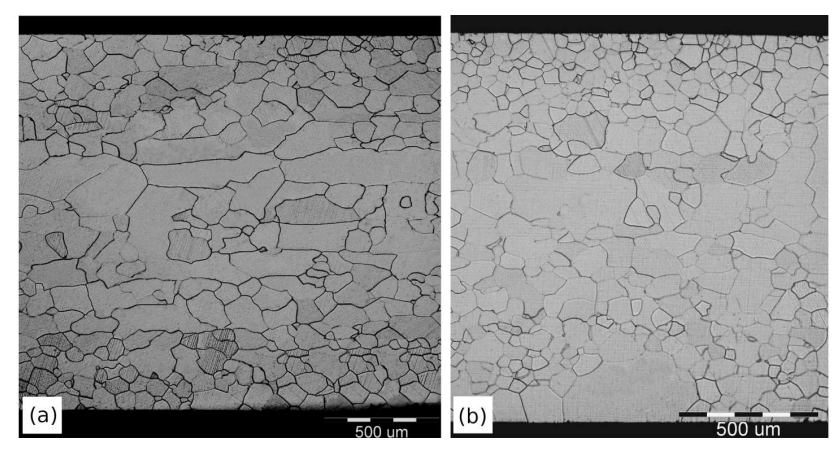

Fig. 2. (a) the structure annealed at $950{ }^{\circ} \mathrm{C} / 20 \mathrm{~min}$, (b) the structure annealed at $1000^{\circ} \mathrm{C} / 20 \mathrm{~min}$.
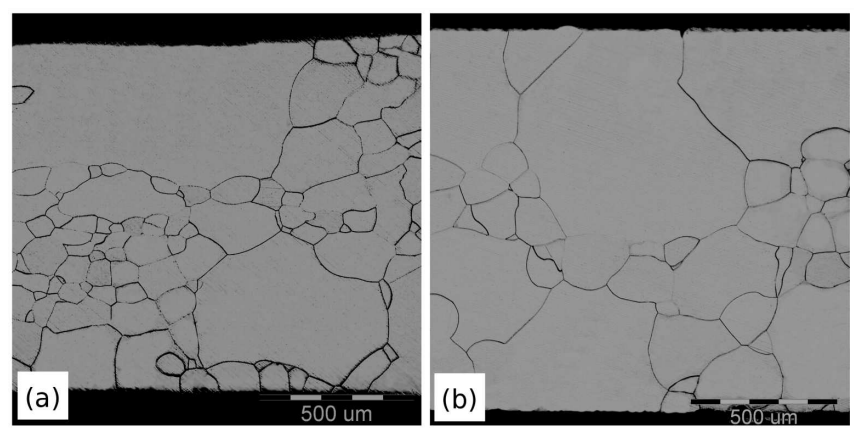

Fig. 3. (a) the structure annealed at $1050{ }^{\circ} \mathrm{C} / 20 \mathrm{~min}$, (b) the structure annealed at $1100{ }^{\circ} \mathrm{C} / 20 \mathrm{~min}$.

ers have higher temperature than the central part). The suppression of dynamic recovery leads to increase of the density of accumulated dislocations, and to the growth of driving force for formation of the large number of nucleation sites for SR. These preconditions were confirmed also by authors $[5,6]$, however for sub-microcrystalline or ultrafine grain structures.

The structures which are being formed in cryogenic conditions, after annealing at temperature of $800^{\circ} \mathrm{C} / 20 \mathrm{~min}$, are characterized by reducing of twins and deformation bands as is shown in Fig. 1b. Only some grains contained the twins. The structures of surface layers could be classified as a static recrystallized. The suppression of dynamic recovery in cryogenic conditions leads to formation of the large number of nucleation sites for SR. The central part of the sample could be classified as a place where partial SR is observed. According to the micrograph observation, a portion of the static recrystallized structures increases from surface layers to central parts i.e. from finest to coarser structures. When annealing temperature was increased to $950^{\circ} \mathrm{C} / 20 \mathrm{~min}$, there can be recognized the full SR structure as is shown in Fig. 2a. If annealing temperature was increased to $1000^{\circ} \mathrm{C} / 20 \mathrm{~min}$, there can be recognized a mixed structure, characterized by $60 \%$ full SR region and $40 \%$ region with abnormal grain growth (Fig. 2b).

When annealing temperature was increased to $1050^{\circ} \mathrm{C} / 20 \mathrm{~min}$, there can be recognized an increase in a portion of the abnormal grain growth, as is shown in Fig. 3a. The full abnormal grain growth was obtained in the following annealing conditions: $1100{ }^{\circ} \mathrm{C} / 20 \mathrm{~min}$ (Fig. 3b). The formation of coarse grain structures is one way to achieve low magnetic losses in NGOES and their higher efficiency for application in e.g. electrical automobile engines and hybrid motors.

\section{Conclusions}

1. The suppression of the dynamic recovery in cryogenic conditions leads to formation of a large number of the nucleation sites on grain boundaries as well as inside the grains.

2. During the annealing process, stress-strain and temperature gradient in the sample thickness, resulting from the cryorolling, should act as the driving force for initiation of the SR of the material.

3. A visible influence on the grain growth was observed after rolling at cryogenic temperature and the followed annealing at $1100^{\circ} \mathrm{C} / 20 \mathrm{~min}$. These processing conditions can provide low magnetic losses in FeSi steel samples.

\section{Acknowledgments}

This work was supported by the Slovak national agency VEGA 1/0359/11.

\section{References}

[1] H.K.D.H. Bhadeshia, Bull. Pol. Acad. Sci. 58, 255 (2010).

[2] E.V. Pereloma, B.R. Crawford, P.D. Hodgson, Mater. Sci. Eng. A 299, 27 (2001).

[3] T. Kvačkaj, J. Bacsó, J. Bidulská, M. Lupták, I. Pokorný, M. Kvačkaj, M. Vlado, Acta Metall. Slovaca 16, 268 (2010).

[4] G. Anand, A. Sinha, P.P. Chattopadhyay, Mater. Manuf. Process. 28, 242 (2013).

[5] Y. Wang, M. Chen, F. Zhou, E. Ma, Nature 419, 912 (2002).

[6] N. Rangaraju, T. Raghuram, B.V. Krishna, K.P. Rao, P. Venugopal, Mater. Sci. Eng. A 398, 246 (2005). 